Sameh Mahmoud shaaban/ Engineering Research Journal 165 (march 2020) M22-M39

\title{
Performance Enhancement of an Integrated Solar Combined Cycle with Multi-Stage Flash Desalination Cycle as Bottoming Cycle
}

\author{
M. Eladawy, E. Elgendy, S. Shaaban \\ Mechanical Engineering Department, College of Engineering and Technology-Cairo Campus, \\ Arab Academy for Science, Technology and Maritime Transport (AASTMT), Cairo, Egypt \\ Corresponding author. \\ E-mail address: Mahmoudeladawy85@Gmail.com.
}

\begin{abstract}
Integrated solar combined cycle (ISCC) is frequently used in countries with high incident solar radiation in order to enhance the cycle efficiency by increasing the net output power and decreasing fuel consumption. The present study proposes a modified ISCC is gas cycle with a steam Rankine cycle and integrated with a multi-stage flash desalination cycle (MSF). The multi-stage compression with intercooling is taken into consideration for the gas turbine unit while the MSF is used in order to cool the compressed air and produce distillate water from the received thermal energy. $50 \mathrm{MW}$ solar field are integrated to steam power cycle. The amount of solar energy and ambient temperature data are obtained from weather data from TRNSYS software as actual data of the two Egyptian cities, Elarish and Bernis. The results of the proposed cycle show improvement by $20.76 \%$ more than the original cycle. Furthermore, the proposed cycle produces $130.6 \mathrm{MW}$ average monthly net power and $4950 \mathrm{M}^{3} /$ day average monthly freshwater in summer while it produces $133.9 \mathrm{MW}$ average monthly net power and $3470 \mathrm{M}^{3} /$ day average monthly freshwater in winter.
\end{abstract}

Keywords: ISCC, gas turbine, steam cycle, MSF, solar energy. 


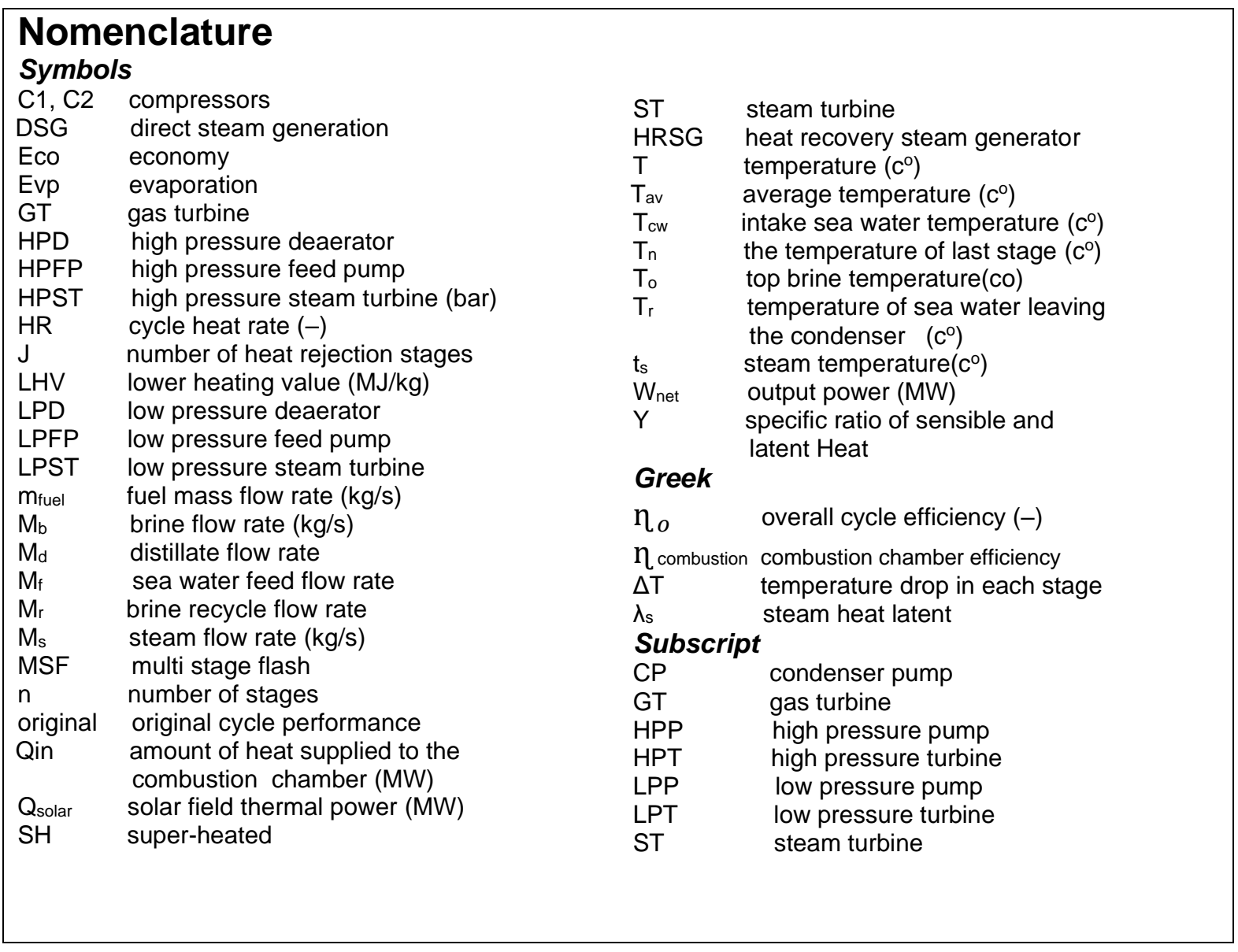

\section{Introduction}

Our planet has been suffering from various types of pollution problems due to the excessive use of fossil fuels. In fact, the different applications of power generation and transportation have been doing substantially great harm to the environment. As a result, scientific attention has been directed towards renewable energy resources. The need to rely on clean and renewable forms of energy has significantly increased for many reasons including fossil fuel degradation, pollution issues and continuous increase oil prices. The key focus of most researches on renewable energy is the sun since the sun is the main source of renewable energy for our planet and almost 170,000 TW of solar radiation falls on Earth each year [1]. concentrated solar power plants are suitable for areas exposed to large amounts of solar radiation, such as North Africa, the Middle East, South Africa, China and the southern United States. Today, solar thermal power plants range from a few megawatts to more than 400MW [2]. However, the solar energy is not enough for power production throughout a day. So, scientists focus on combining renewable resources together as one of the solutions to eliminate fossil fuel consumption. 
The issue of energy demand and supply is a major concern for most countries nowadays. Studies show that the energy supply can be increased by increasing the renewable energy share and enhancing the efficiency of existing power plants. In order to improve the electrical power production and reduce the amount of burnt fusel fuel, renewable energy resources, like biogas or solar energy, can be integrated with traditional combined cycle power plants. Thus, large number of commercial Integrated Solar Combined Cycle (ISCC) power plants are currently under construction or operation. Egypt has successfully constructed an Integrated Solar Combined Cycle (ISCC) power plant in Kureimat. The solar field of the Kureimat project adds $20 \mathrm{MW}$ to the output power of the traditional combined cycle which produces 120 MW of electricity. Although many techniques are available nowadays to harvest the solar energy [3-5], the ISCC utilizes the solar thermal energy as one beneficial way that could reduce the amount of burnet fusel fuel. In addition, integrating the solar thermal energy with the high efficiency combined cycle could significantly reduce both the cost of electricity and the emissions.

There have been a number of previous studies conducted on improving ISCC power plants. For instance, Montes et al. [6] examined the performance of an ISCC power plant with a Direct Steam Generation (DSG) parabolic-trough field coupled to the bottoming steam cycle of a combined cycle. They found out that this hybrid scheme is significantly a cheaper way to utilize concentrated solar energy. Also, Rovira et al. [7,8] investigated the performance of ISCC with heat transfer fluid and DSG technologies. They concluded that the only-evaporative DSG configuration is obviously the best alternative to enhance the performance of ISCC. Li et al. [9] proposed a novel cascade ISCC system in which a concentration solar collector (e.g. parabolic troughs) was used as a direct steam generator while a non-concentration collector (e.g. evacuated tubes) was hybrid with a combined cycle power plant. They could successfully achieve the goal of getting a low-cost and high conversion efficiency from their proposed hybrid system. Similarly, Zhu et al. [10] proved that a substantial benefit from the solar hybridization of a natural gas combined cycle power plant with regard to a thermodynamics point of view can be achievement. Shaban.S [11] proposed an approach to extract energy from intercooling heat exchanger of two stage compression to produce water and electricity. Ozturk and Dincer [12] studied a system in which power, heat, hot water, cooling and hydrogen are generated by the use of energy input. They combined organic Rankine, Rankine, absorption and hydrogen cycles in one system. In general, most of the previous studies show that the production of multiple outputs from one system could improve overall efficiency of power plants [12-16].

Several countries, especially those which suffer from freshwater shortage, utilize different ways to produce freshwater by desalinating sea water. In fact, about 80 countries face the scarcity of freshwater throughout the world [17]. It is also observed that the worldwide $27 \%$ of desalination plants are thermally driven [18]. What is significant with regard to the multi-Stage flash desalination system (MSF) is that it operates at relatively lower temperature (under $100{ }^{\circ} \mathrm{C}$ ) [19]. Concerning the structure of MSF, it consists of several 
stages where in each stage pressure is kept lower than the previous stage in order to flash the steam. In the present study, MSF with three stages is proposed.

Although Egypt depends on the Nile River as the main source of fresh water, the problem of potable water shortage may rise as a direct result of increasing population. Consequently, the recommendations of using economically admissible methods to produce drinking water are regarded as highly crucial issues. In this respect, desalination of salt water has become an increasingly essential industrial activity throughout the world. Nowadays, it is observed that most of the Middle East countries use the multi-stage flash (MSF) desalination technique to produce drinking water. Thermal desalination processes are common techniques for producing drinking water in the Middle East countries. The main idea of thermal desalination is the distillation process in which brackish water or seawater is converted to potable water appropriate to be used in domestic and industrial activities.

Once a thermal desalination system is constructed in a power plant, the thermal energy required for distillation would be obtained by heat recovery of waste energy produced from any sections of the power plant [20,21]. Despite the fact that there are a number of conventional thermal desalination methods including vapor compression (VC), multieffect distillation (MED) and multi-stage flash distillation (MSF), the MSF desalination system is apparently more common than the other systems [22, 23]. Researches confirm that approximately $65 \%$ of the world's desalination plants use MSF desalination technology and more than $80 \%$ of seawater desalination in Gulf countries is based on MSF desalination technique [24, 25]. For example, Kuwait, Qatar, Oman, United Arab Emirates and Saudi Arabia are some of the Arab countries that substantially use MSF desalination techniques [21,26-28]. The fact that some power plants are going to be constructed or have been already constructed on the Red Sea makes it considerably valuable to design and construct some thermal desalination plants in this area.

To sum up, the main focus of the study at hand is to introduce an efficient MSF desalination plant in Elarish city supplied by a heat recovery from intercooling compression stage, with respect to the limitations of salinity $(70,000 \mathrm{ppm})$. Thus, practical correlations are performed to design the MSF desalination system and then to determine the required operating parameters.

The study at hand aims at improving the conversion of thermal energy into electricity and distillate water using the integrated solar combined cycle (ISCC) power plants and a multi-stage flash desalination (MSF). It examines the performance of the Integrated Solar Combined Cycle (ISCC) power plants and a multi stage flash desalination (MSF) in two different Egyptian cities. The first city, Elarish, is located on the Mediterranean Sea in the north of Egypt and the other, Bernis, located on the Red Sea in south-east of Egypt as shown in figure 1. In addition, the present study proposes a novel ISCC power plant with one bottoming cycle. Fig. 2 shows a schematic representation of the proposed ISCC with the two bottoming cycles. This cycle was obtained by modifying the gas turbine unit of 
the ISCC power plant as examined by Rovira et al. [8] and inserting the MSF as a second bottoming cycle. The proposed cycle applies the only-evaporative DSG configuration as recommended by Rovira et al. [7].

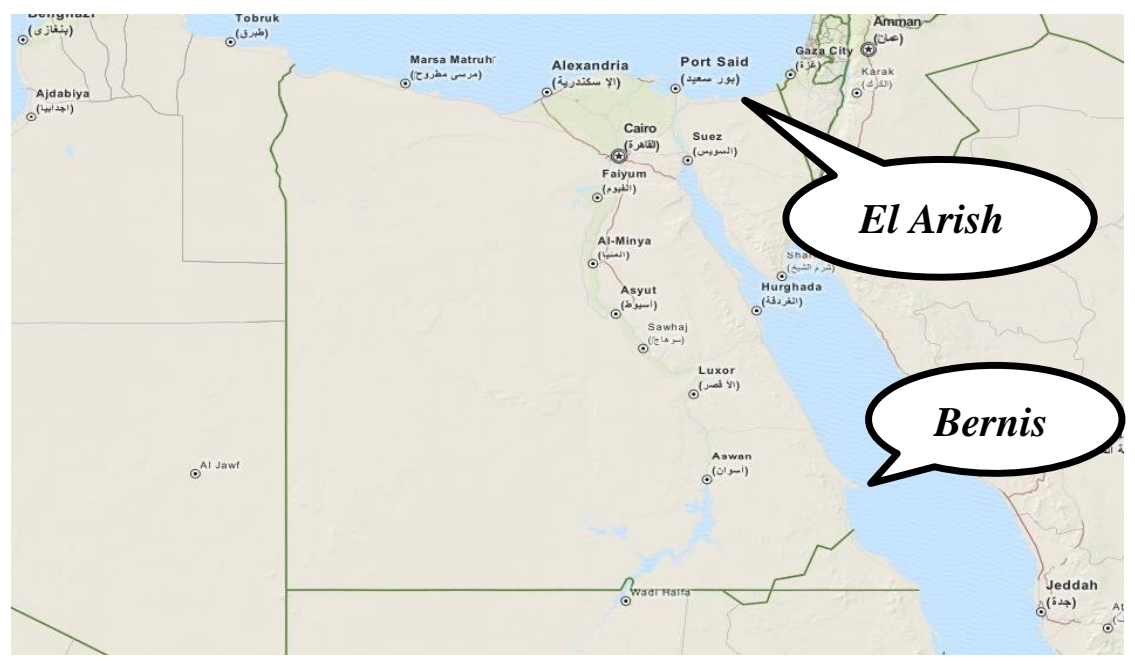

Figure 1. Arab Republic of Egypt map.

\section{Cycle performance simulation}

Fig. 2 shows the proposed cycle with numbers and letters distinguishing the different locations of the cycle. The cycle is thermos-dynamically analyzed by simulating it through the use of the Engineering Equation Solver (EES) software. The two basic elements of weather data, solar energy field and ambient temperature, are obtained from TRNSYS software hour by hour throughout the year. Table 1 shows the technical data of the proposed cycle at nominal conditions. The pressure and temperature of the steam at different locations (Table 1 and Fig. 2) as well as the overall compressor pressure ratio, air mass flow rate, fuel mass flow rate and the temperature of gas turbine inlet and outlet are identical to those of Rovira et al. [8]. Thereby, comparison of the proposed cycle performance with the data of Rovira et al. [8] is possible. According to the present study, the ISCC of Rovira et al. [8] is called "the original cycle". The proposed cycle shown in Fig. 2 was simulated by the EES software using 327 equations that describe each location and component of the cycle. The mass flow rates of the steam and the sea water are estimated at different weather operating 
Sameh Mahmoud shaaban/ Engineering Research Journal 165 (march 2020) M22-M39

conditions by solving these 327 equations simultaneously. Thereby, the compressor power, the gas turbine power, the steam turbines power and the MSF Heat exchanger are estimated according to the different weather operating conditions throughout the year. The overall cycle efficiency is estimated from the following equation:

$\eta_{o}=\frac{W_{\text {net }}}{Q_{\text {in }}+Q_{\text {solar }}}$

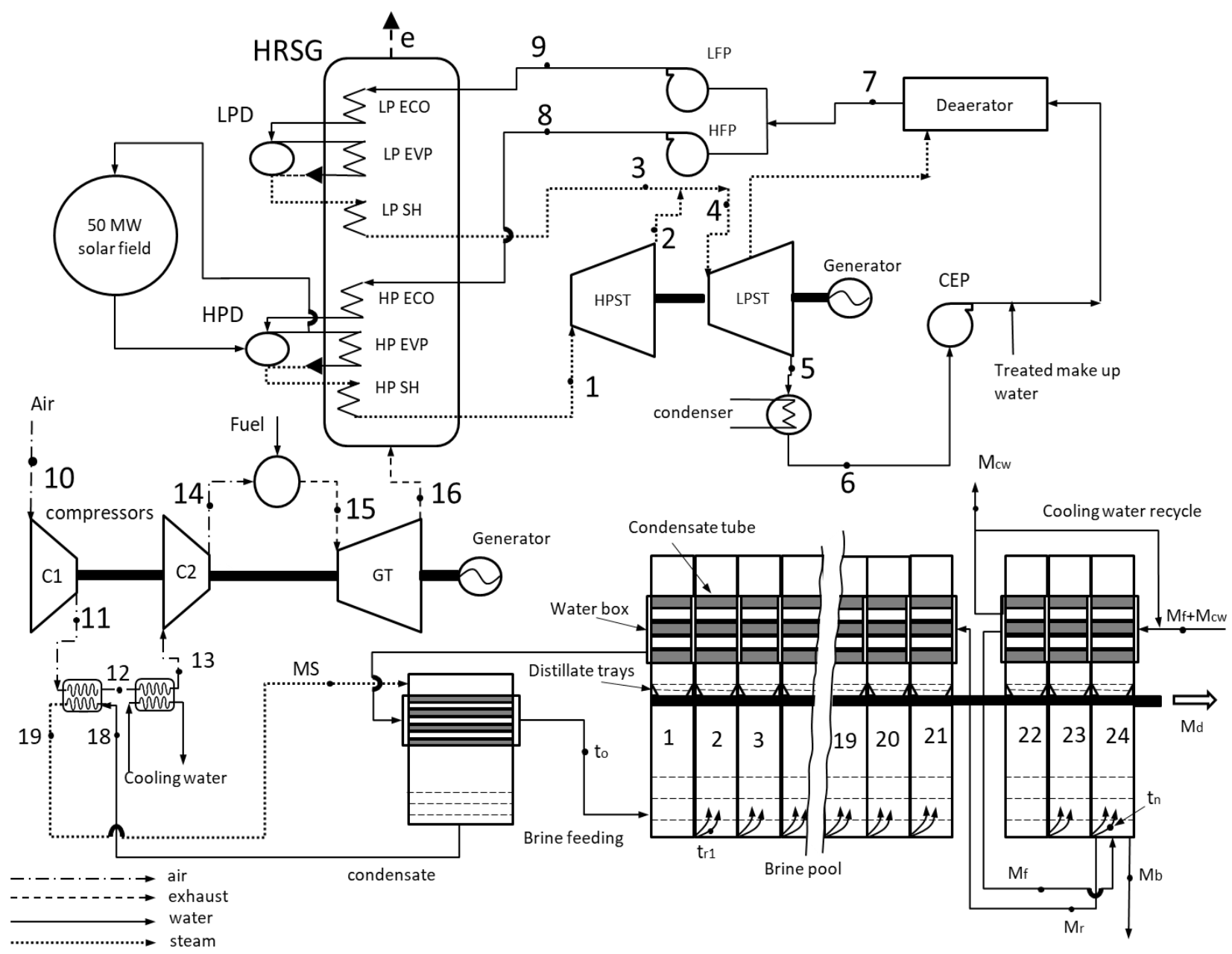

The net power $\mathrm{W}_{\text {net }}$ is the summation of the net power of the two cycle

$W_{n e t}=W_{G T}+W_{s t}$

The net power $\mathrm{W}_{\mathrm{GT}}$ is the net power of the gas power cycle

$W_{G T}=W_{T}-W_{C}$ 
The power $\mathbf{W}_{\mathbf{T}}$ is the power of the gas power turbine

$W_{T}=\left(\boldsymbol{m}_{\text {air }}+\boldsymbol{m}_{\text {fuel }}\right) *\left(\boldsymbol{c} \boldsymbol{p}_{\text {exh15 }} * \boldsymbol{T}_{\mathbf{1 5}}-\boldsymbol{c} \boldsymbol{p}_{\text {exh16 }} * \boldsymbol{T}_{\mathbf{1 6}}\right)$

The power $\mathrm{W}_{\mathrm{C}}$ is the power of the gas power compressor

$W_{c}=\boldsymbol{m}_{\text {air }} *\left[\left(\boldsymbol{h}_{11}-\boldsymbol{h}_{10}\right)+\left(\boldsymbol{h}_{14}-\boldsymbol{h}_{13}\right)\right]$

The net power $\mathrm{W}_{-}$net_ST is the net power of the steam power cycle

$W_{S t}=W_{H P T}+\bar{W}_{L P T}-\left[W_{H P P}+W_{L P P}+W_{C E P}\right]$

The amount of heat supplied to the cycle was estimated from:

$\mathbf{Q}_{\text {in }}=\boldsymbol{m}_{\text {fuel }} * \mathbf{L H V} * \eta_{\text {combustion }}$

The total summation of the distillate water formed in all stages was estimated from

$\boldsymbol{M}_{\boldsymbol{d}}=\boldsymbol{M}_{\boldsymbol{r}} *\left[\mathbf{1}-(\mathbf{1}-\boldsymbol{y})^{n}\right]$

The brine recycle flow rate is obtained from:

$\boldsymbol{M}_{r}=\frac{\mathbf{M}_{\mathbf{s}} * \lambda \mathbf{s}}{\mathbf{c}_{\mathbf{p}} *\left(\mathbf{t}_{\mathbf{o}}-\mathbf{t}_{\mathbf{r} 1}\right)}$

The steam flow rate is calculated from:

$M_{s}=\frac{\mathbf{Q}_{\text {intercool }}}{\mathbf{h}_{19}-\mathbf{h}_{18}}$

The amount of heat extracted from intercooling stage of heat exchanger which is added to a multi-stage flash cycle is calculated from:

$\mathbf{Q}_{\text {intercool }}=$ mair $*\left(h_{11}-h_{12}\right)$

The specific ratio of sensible heat and latent heat is calculated from:

$\mathbf{y}=\frac{(\mathbf{c p} * \Delta \mathbf{T})}{\lambda \mathbf{a v}}$

The temperature drop per stage is calculated from:

$$
\Delta \mathbf{T}=\frac{(\text { to }- \text { tn })}{\mathbf{n}}
$$

The sea water temperature leaving the condenser at the first stage is calculated from:

$$
\boldsymbol{T}_{\boldsymbol{r} \mathbf{1}}=\boldsymbol{T}_{\boldsymbol{n}}+[(\mathbf{n}-\mathbf{j}) * \Delta \mathbf{T}]
$$

The amount of heat supplied to the HRSG from the solar field $\mathbf{Q}$ solar is obtained from TRNSYS as actual weather data. It should be mentioned here that simulation of the cycle performance without solar thermal energy was also performed. Eq. (1) shows that the overall efficiency decreases with increasing the solar energy contribution. Therefore, the heat rate HR is used to express the cycle performance:

$\mathbf{H R}=\frac{\mathbf{Q}_{\text {in }}}{\mathbf{W}_{\text {net }}}$ 
The low values of the heat rate HR mean lower specific fuel consumption of the power plant. The heat rate HR is the reciprocal of the cycle overall efficiency of the power plants without solar contribution. Based on an extensive literature survey, MSF is selected and investigated to make heat recovery and to extract heat from intercooling compression gas power cycle. The cycle performance simulation model is first established and executed without either the MSF or the compressor multi-stage compression with intercooling. The results are compared to those of Rovira et al. [8] in order to verification the model. The model can significantly reproduce all the operating parameters and conditions of the ISCC as proposed by Rovira et al. [8].

Table 1. Technical data of the cycle at nominal conditions

\begin{tabular}{ll|}
\hline Ambient pressure & $1 \mathrm{bar}$ \\
Overall compression ratio & $16: 1$ \\
Air mass flow & $210 \mathrm{~kg} / \mathrm{s}$ \\
Exhaust gas flow & $214 \mathrm{~kg} / \mathrm{s}$ \\
Gas turbine inlet temperature & $1450 \mathrm{~K}$ \\
Gas turbine outlet temperature & $828 \mathrm{~K}$ \\
Compressor isentropic efficiency & $85 \%$ \\
Gas turbine isentropic efficiency & $90 \%$ \\
Combustion chamber efficiency & $98 \%$ \\
Natural gas lower heating value & $48 \mathrm{MJ} / \mathrm{kg}$ \\
High pressure steam temperature & $818 \mathrm{~K}$ \\
Steam high pressure & $90 \mathrm{bar}$ \\
Low pressure steam temperature & $566 \mathrm{~K}$ \\
Steam low pressure & $5 \mathrm{bar}$ \\
Pinch point & $10 \mathrm{~K}$ \\
Steam turbine isentropic efficiency & $87 \%$ \\
Pump efficiency & $75 \%$ \\
\hline
\end{tabular}

\section{Methodology}

The present research is simulated by using TRNSYS and EES software linked with each other and operating at the same time. The first software, TRNSYS, is used to obtain the ambient temperature and solar energy from weather data stored in (type 109) according to the location of cycle. The solar energy is received by linear parabolic concentrated collector (type 536) to obtain useful energy. The EES software which is linked with TRNSYS software by (type 66a) receives useful solar energy and ambient temperature hour by hour throughout the year and uses it as inputs data to the cycle which is simulated by EES software using 327 equations simultaneously as shown in figure (3) and (4): 


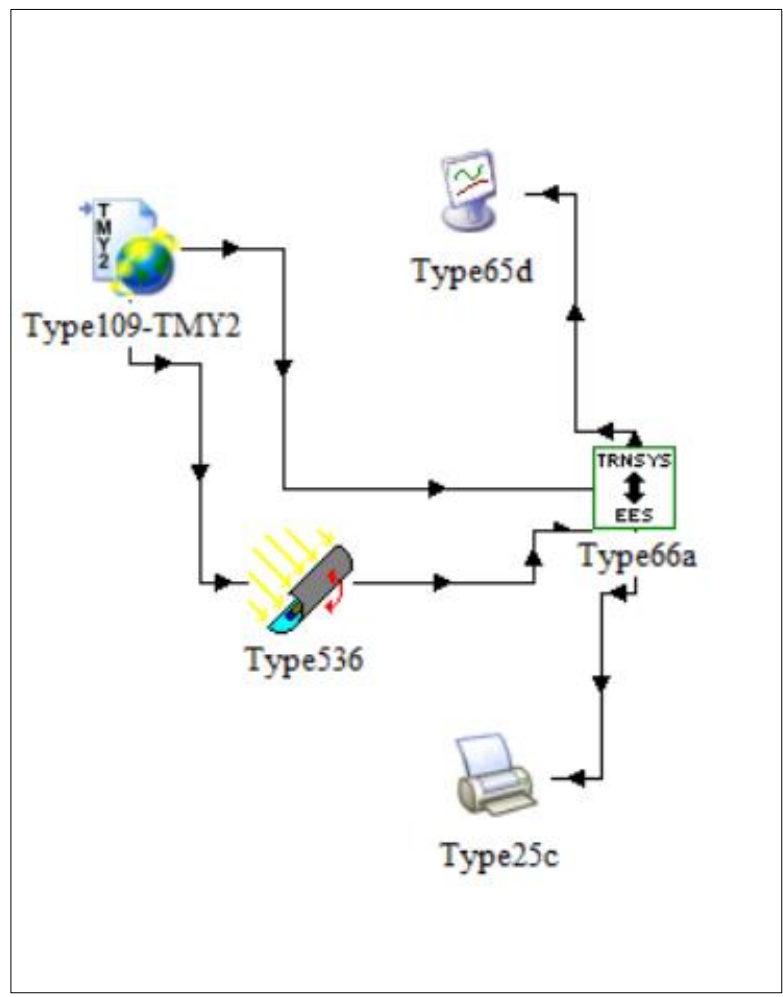

Figure 3. TRNSYS software schematic

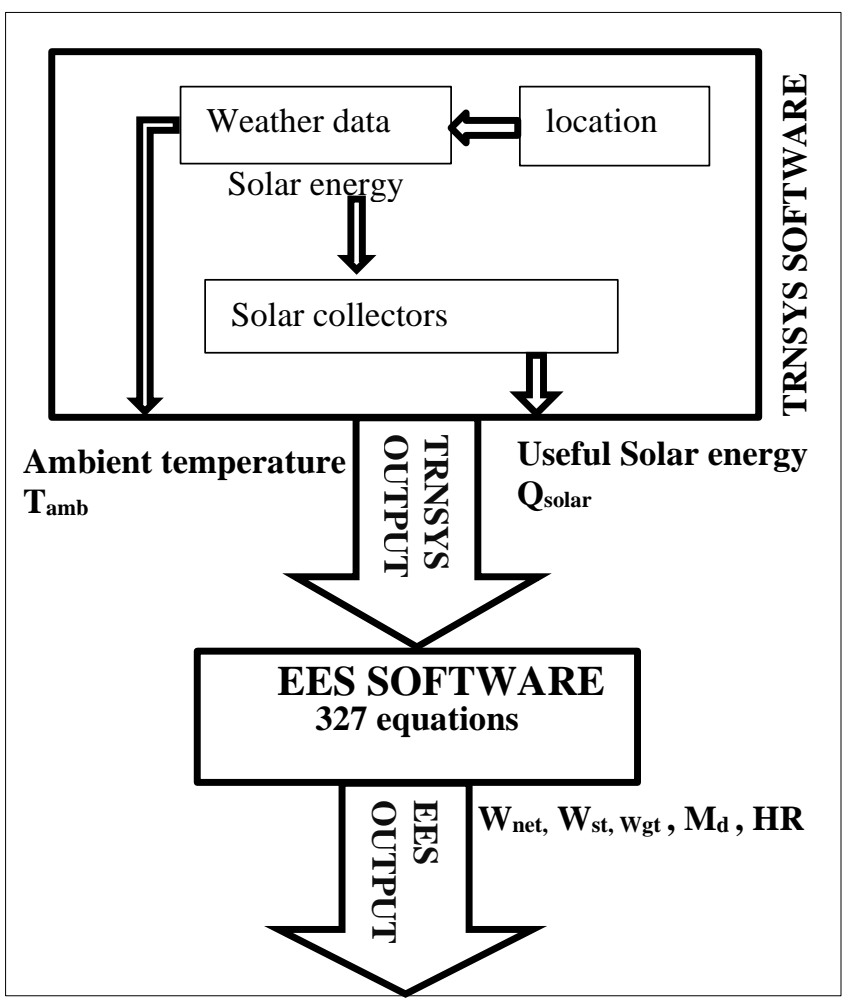

Figure 4. Flowchart of the cycle simulation

\section{Results and discussion}

The present research proposes an integrated solar combined cycle (ISCC) with a steam Rankine cycle and multi-stage desalination Cycle (MSF) as bottoming cycles. The MSF cycle was implemented in the present work in order to improve the gas turbine output power by means of compressor intercooling while producing a net output power, as shown in Fig. 1. The cycle performance was simulated for working in two Egyptian cities, Elarish and Bernis, with actual weather data obtained from TRNSYS software according to the method described in Section 3. Tables 2,3 present the average monthly ambient temperature and useful solar energy in Elarish and Bernis cities.

Table 2. average monthly ambient temperature $\left(\mathrm{C}^{\circ}\right)$ obtained from TRNSYS

\begin{tabular}{|l|l|l|l|l|l|l|l|l|l|l|l|l|}
\hline & Jan & Feb & March & April & May & June & July & Aug & Sep & Oct & Nov & Dec \\
\hline Elarish & 12.63 & 13 & 15.05 & 18.18 & 21.01 & 24.05 & 25.99 & 26.24 & 24.02 & 21.87 & 17.4 & 13.93 \\
\hline Bernis & 15.3 & 17.37 & 21.8 & 26.59 & 31.37 & 33.04 & 33.64 & 33.23 & 30.8 & 27.8 & 21.22 & 16.9 \\
\hline
\end{tabular}

Table 3. average monthly useful solar energy (MW) obtained from TRNSYS

\begin{tabular}{|l|l|l|l|l|l|l|l|l|l|l|l|l|}
\hline & Jan & Feb & March & April & May & June & July & Aug & Sep & Oct & Nov & Dec \\
\hline Elarish & 2.48 & 3.86 & 5.71 & 7.98 & 10.08 & 11.19 & 10.96 & 9.26 & 7.02 & 4.52 & 2.83 & 2.03 \\
\hline Bernis & 4.16 & 5.8 & 7.89 & 10.05 & 11.21 & 11.57 & 11.26 & 10.33 & 8.57 & 6.29 & 4.58 & 3.74 \\
\hline
\end{tabular}

Fig. 5. presents the cycle heat rate for the original cycle (Rovira [8]) and the proposed cycle of the present study with the same ambient temperature and solar energy obtained from TRNSYS software. The figure shows the average value for the heat rate for each 
month. The results of the proposed cycle show good thermodynamic performance with regard to the original cycle in Elarish city. The results show that the heat rate of the proposed cycle is $20.76 \%$ less than the original one.

Fig.6. shows the effect of change in design between the original and proposed cycle in gas power cycle on the output power from gas power cycle to two cycles in Elarish city. The proposed cycle output power of gas cycle is $20.76 \%$ higher than the original cycle due to compressor intercooling.

Fig.7. shows the output power from the steam cycle of original and proposed cycle. The results show that there is no significant difference in output power because there is no difference in the design of steam cycle between the original and proposed cycle in Elarish city.

Fig.8. shows the net power output which is the summation of the power obtained from gas power cycle and steam power cycle in Elarish city. The proposed cycle net power

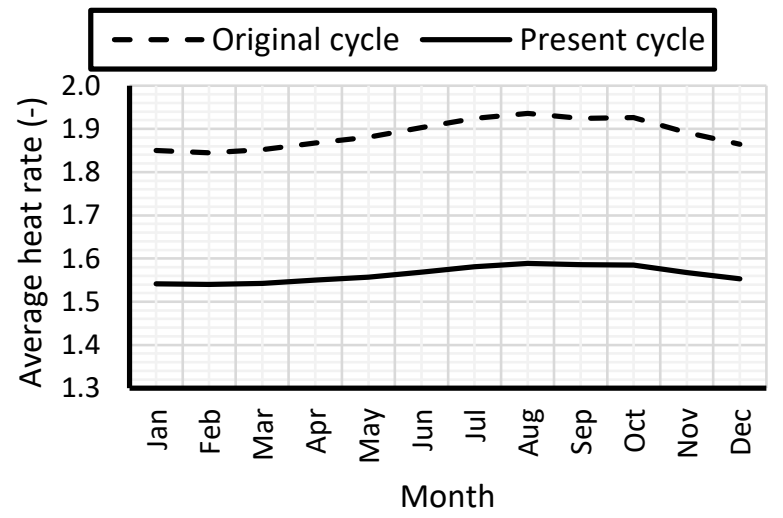

Figure 5. Monthly analysis of the heat rate to original and present cycle.

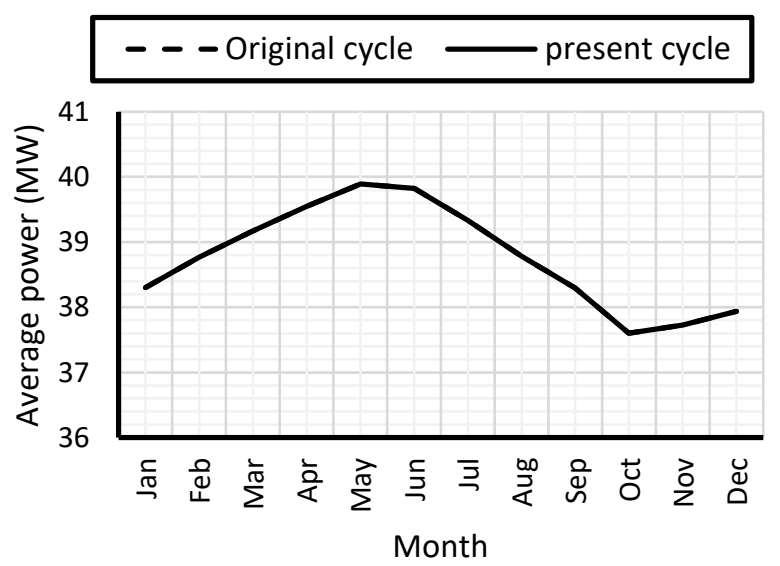

Figure 7. Monthly analysis of the net power produced by steam cycle in original and present cycle.

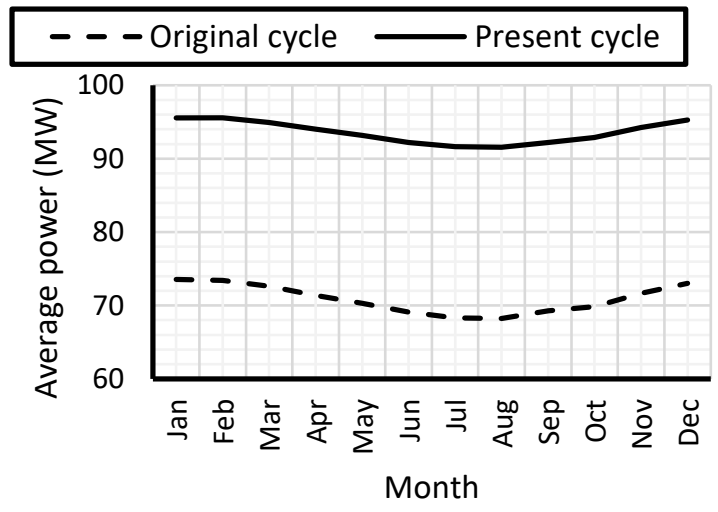

Figure 6. Monthly analysis of the net power produced by gas cycle in original and present cycle.

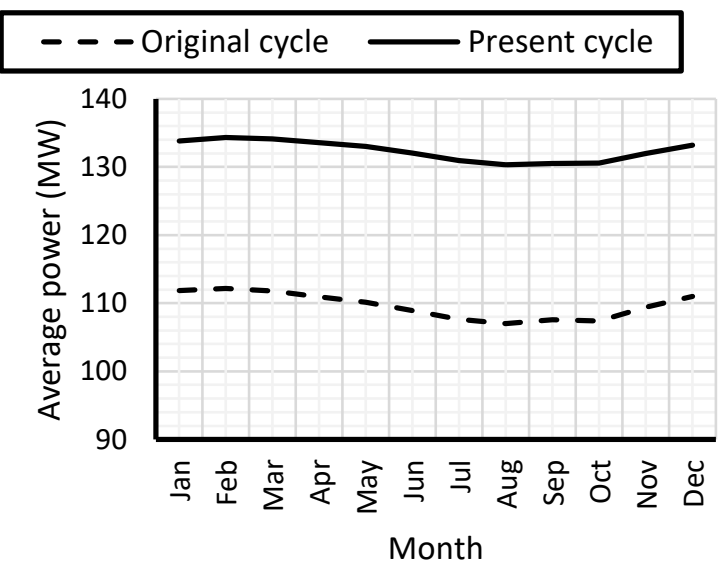

Figure 8. Monthly analysis of the net power produced by original and present cycle. 
cycle is $20.76 \%$ higher than the original cycle with actual ambient temperature and solar energy hour by hour throughout the year.

Fig.9. Shows the effect of the variation of ambient temperature and the freshwater production. The value of freshwater production flow rate increases by increasing the value of ambient temperature. The increase of ambient temperature $\left(\mathrm{t}_{\mathrm{amb}}\right)$ leads to increasing the outlet temperature of the compressor which, in turn, results in increasing the amount of heat transfer to intercooling heat exchanger of two stages compression as shown in equation (11). The increase of the steam generation flow rate (Ms) to (MSF) as shown in equation (10) leads to increasing of recycling brine rate (Mr) as shown in equation (9) which subsequently increase the rate of freshwater production as shown in equation (8).

Fig.10. shows monthly analysis of average distillate water production in the two Egyptian cities: Elarish and Bernis. The chart shows differences in the production of freshwater in the two cities due to their differences in weather data. The chart shows that the production of freshwater in Elarish is less than that of Bernis. Such a difference could be explained by the increase of ambient temperature in Bernis than Elarish due to approach of Bernis to the equator. In Elarish, the average production of freshwater in July is 4960 M3/day and in January is 3476.2 M3/day. The change in location from Elarish to Bernis adds $16.4 \%$ to the production of distillate water.

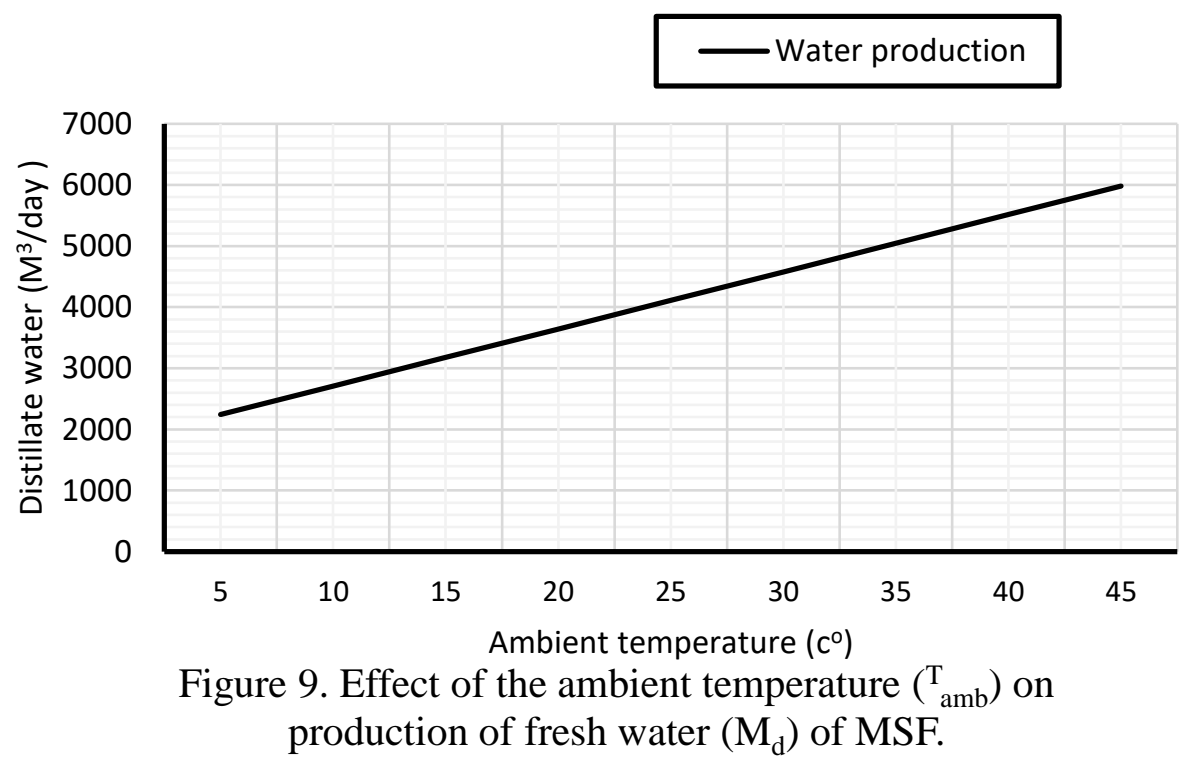




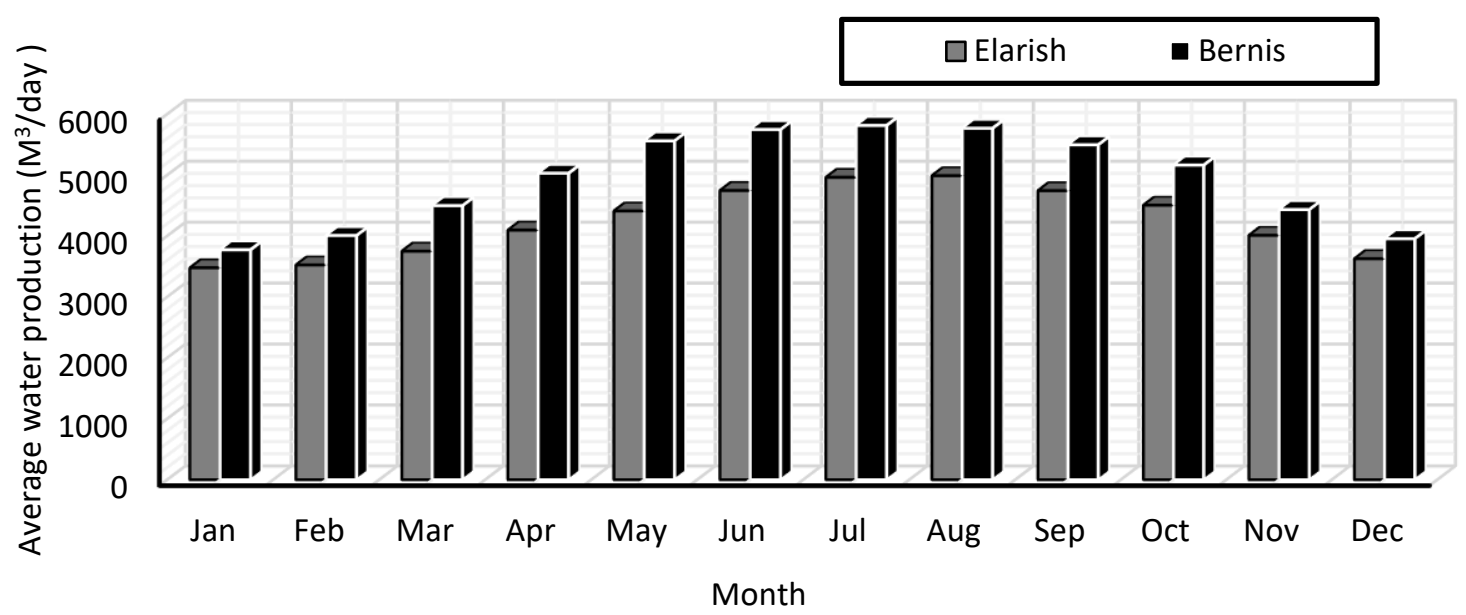

Figure 10. Monthly analysis of the average distillate water production.

Fig.11. shows the effect of the variation of ambient temperature and the net power. The value of net power decreases by increasing the value of ambient temperature. Fig.12. shows monthly analysis of average net power of combined power cycles for the two cities: Elarish and Bernis. The chart shows differences in the average net power of combined power cycles between the two cities as a direct result to the differences in weather data between the locations of the two cities.

The chart in Fig.12. shows that the average net power of power cycles in Elarish is more than the average net power of Bernis due to increasing the ambient temperature of Bernis than that of Elarish which resulted from the approach of Bernis to the equator. In Elarish, the average net power on July is 130.9 (MW) and on January is 133.8 (MW). Significantly, the change in location from Bernis to Elarish adds $1.8 \%$ to the net power.

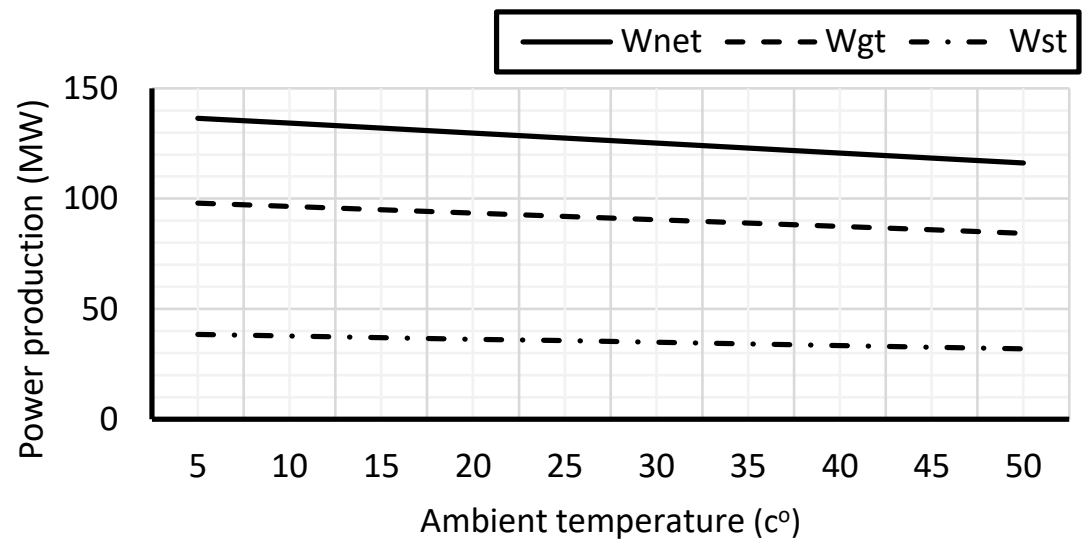

Figure 11. Effect of ambient temperature $\left(\mathrm{T}_{\mathrm{amb}}\right)$ on net power. 


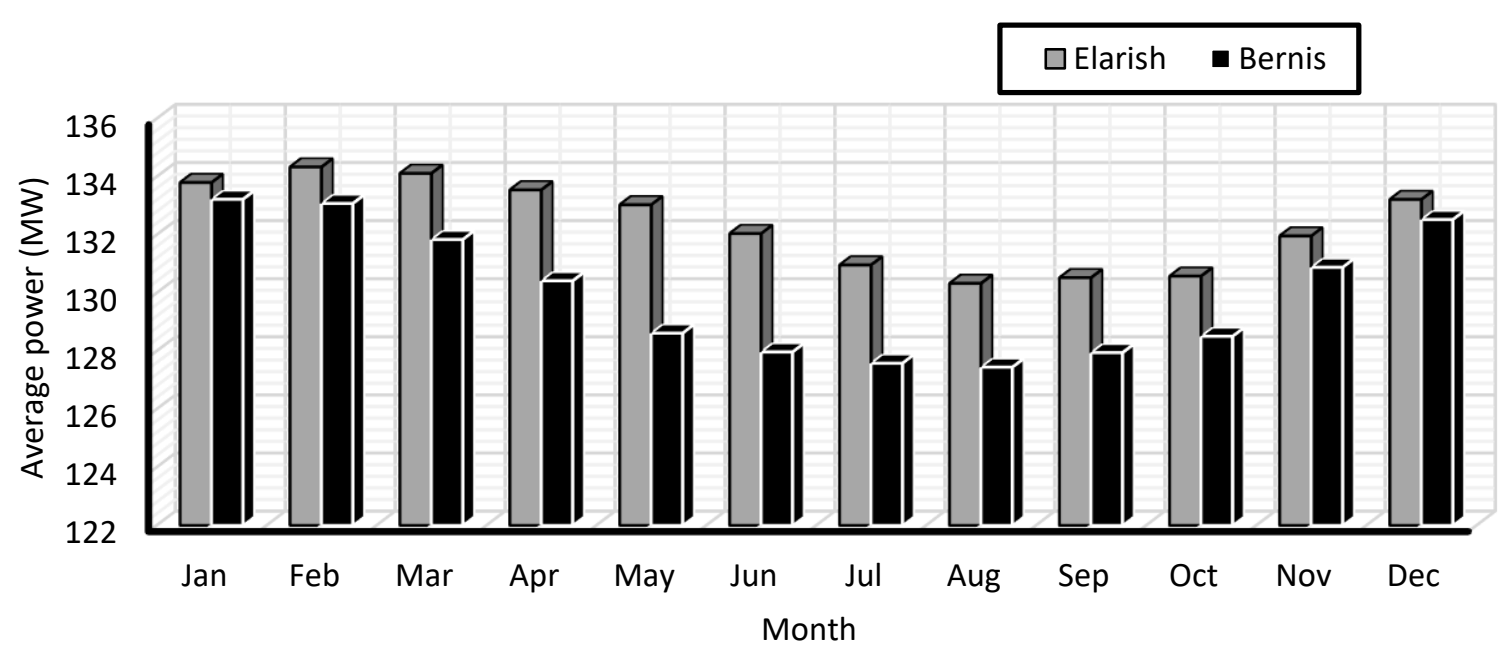

Figure 12. Monthly analysis of the average net power.

Table 4. Recommended average days for months [29].

\begin{tabular}{|l|l|}
\hline Month & Date \\
\hline January & 17 \\
\hline July & 17 \\
\hline
\end{tabular}

Figs. 13 and 14. show the analysis of the production of freshwater during two different days in summer and winter, the 17th of July and the 17th of January respectively. These figures show the differences between seasons and their effect on the productivity of real weather data from solar energy and ambient temperature. The figures show that the productivity on the 17th of July is higher than that in 17th January due to the different ambient temperature of summer and winter. The curves show high productivity at $3 \mathrm{PM}$ which has the highest ambient temperature. The distillate water on the 17th January in Elarish is 3384.6 M3/day while in 17th of July it is 4908.09 M3/day. Figures show higher water production in Bernis than in Elarish throughout the year due to the higher ambient temperature in Bernis. 


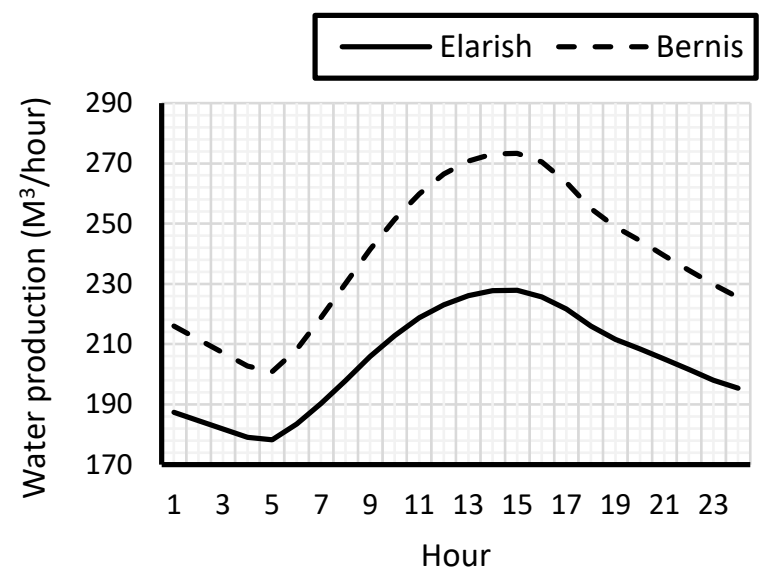

Figure 13. Hourly analysis of distillate water production for $17^{\text {th }}$ July.

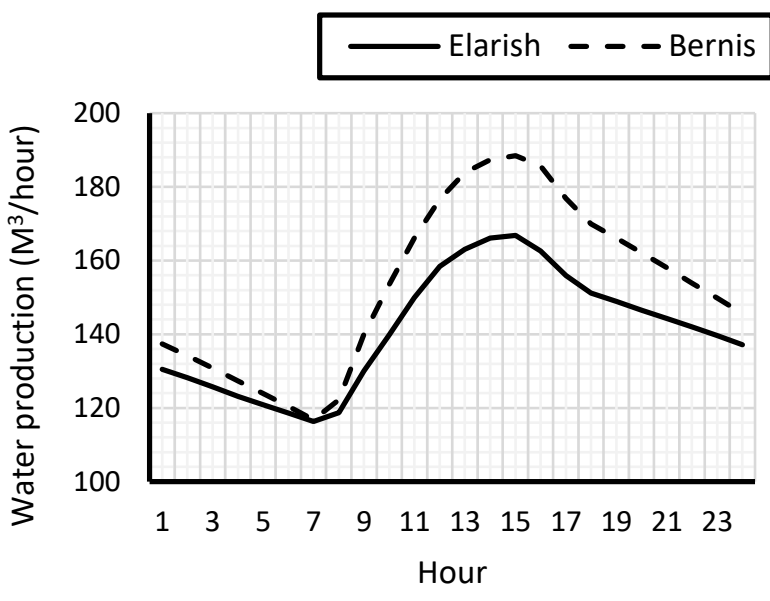

Figure 14. Hourly analysis of distillate water production for $17^{\text {th }}$ January.

Figs. 15 and 16. show hourly analysis of net power in the first day in summer and winter and signify the effect of season climate change. The study curves show the net work of solar contribution. The curve presents the effect of solar energy and ambient temperature on the net work. The net work increases when the ambient air decrease as shown from 1 AM to 9 PM. the net work increases with the increase of the solar energy as shown from 9 AM to 17 PM. The two curves show the difference of net power generation from season to another. While in the summer high solar irradiance adds high solar energy and rises the power of steam cycle, high ambient temperature gives low power in gas cycle the final summation shown in figures.

In figure 16, it is shown that the net work in Elarish is higher than that in Bernis city because obviously the high ambient temperature in summer reduces the net power. In figure 16, it is shown that the net power in Bernis is higher than that in Elarish from 10 AM to 16 PM because the solar energy and the net power in Elarish is higher than those in Bernis during the day without solar contribution as a result to the low ambient temperature in Elarish than in Bernis.

Generally, higher net power gives lower heat rate and lower net power leads to higher heat rate as shown in figures 17 and 18. On the $17^{\text {th }}$ of July, the average heat rate in Elarish is 1.58 and in Bernis it is 1.62 while on the $17^{\text {th }}$ of January, the average heat rate in Elarish is 1.54 and Bernis it is1.55. 


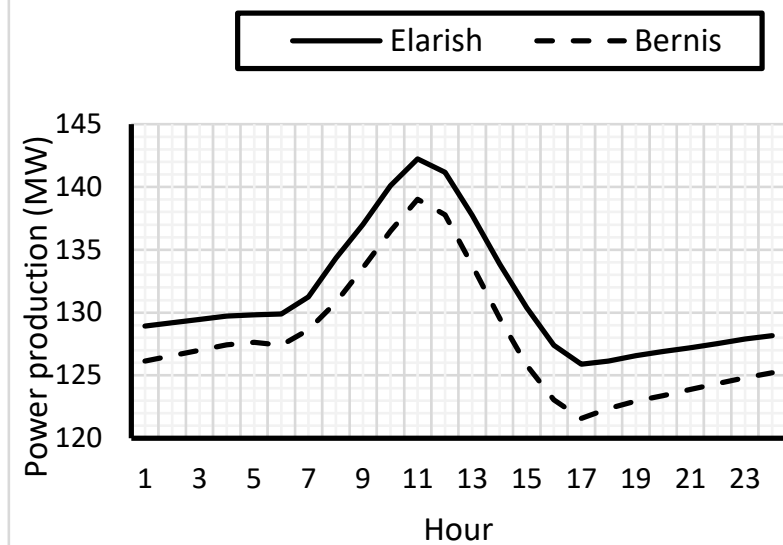

Figure 15 . Hourly analysis of the net power for $17^{\text {th }}$ July .

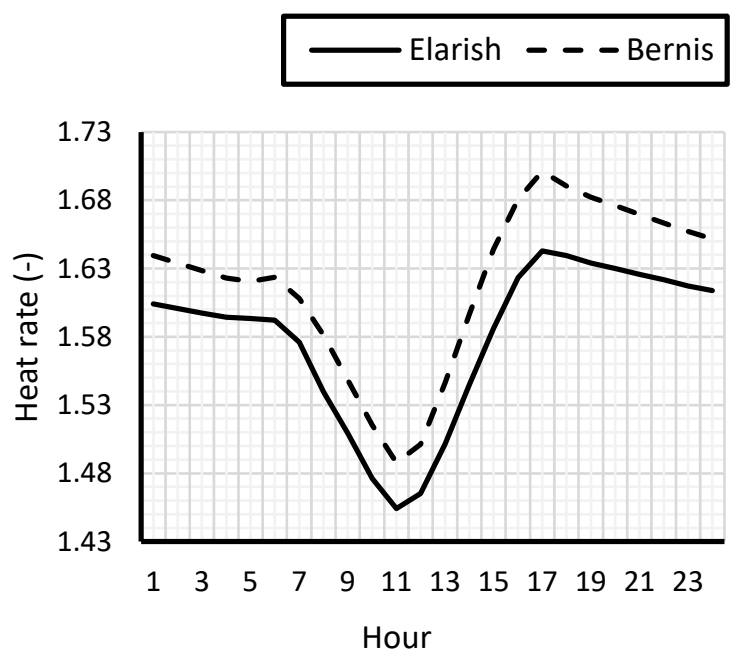

Figure 17 . Hourly analysis of the heat rate for $17^{\text {th }} \mathrm{July}$.

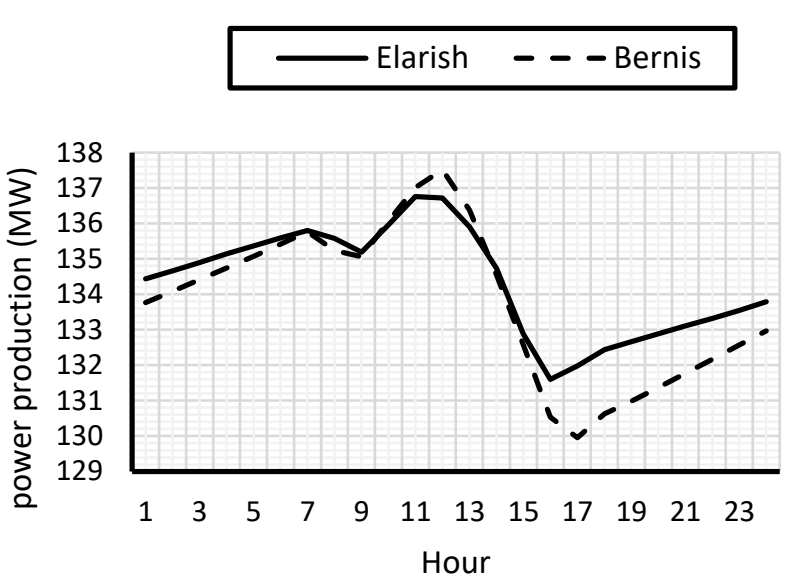

Figure 16. Hourly analysis of the net power for $17^{\text {th }}$ January .

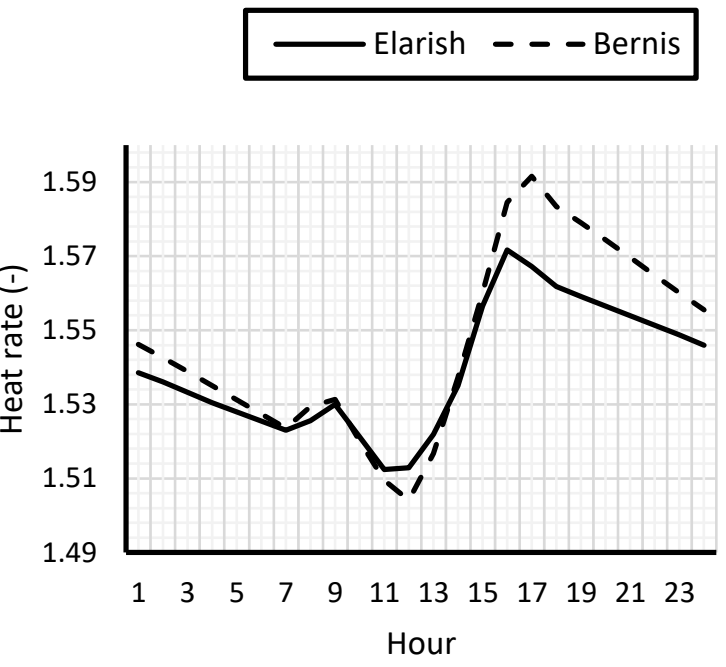

Figure 18. Hourly analysis of the heat rate for $17^{\text {th }}$ January.

\section{Conclusion}

Multi generation from power and freshwater are produced in the present work. Two stages compression with intercooling was used in gas power cycle. Heat recovery obtained from intercooling compressor is used to drive multi-stage flashing desalination unit. The proposed cycle examines the thermodynamics performance and compare it with the thermodynamics performance to the original cycle. The proposed cycle studying in two different locations: Elarish and Bernis, Egypt.

The proposed cycle aims at enhancing the overall performance of the ISCC by reducing the energy loss of the gas turbine unit. The highest energy loss of the gas turbine unit takes place during the air compression as well as the gas exhaust from turbine. Therefore, 
two bottoming cycles are to be used in the current proposed cycle. The first bottoming cycle is the well-known steam Rankine cycle. This cycle saves the high available thermal energy at gas turbine outlet by using it for the generation of steam in a Heat Recovery Steam Generator (HRSG). It also receives thermal energy from a solar field whose values are obtained from weather data of TRNSYS software per hour with a maximum value, 50 MW. The second bottoming cycle is a multi-stage flash desalination (MSF) Cycle. Its function is to reduce the power consumed during the air compression by intercooling the compressor. It also utilizes the thermal energy received from the compressed air to produce distillate water. Thereby, the (MSF) increases the output power of the power plant by reducing the compressor work and generating additional amount of distillate water. These two bottoming cycles significantly increase the net output power of the proposed cycle compared to the traditional ISCC.

The following conclusions are obtained:

(a) The proposed cycle heat rate of the combined power cycle is less than by $20.76 \%$ of the original cycle without compressor intercooling.

(b) The proposed cycle improves the net power of the combined cycle by $20.76 \%$ as compared to the combined cycle to original cycle without compressor intercooling all year. Consequently, the heat rate in Elarish is lower than that in Bernis by $20.9 \%$.

(c) The proposed cycle gives $1.4 \%$ more output power in Elarish compared to Bernis under the same conditions.

(d) Hot ambient temperature in Bernis produces $16.4 \%$ more distillate water than that in Elarish.

(e) The per capita consumption rate for household purposes is 200 liters/day, which is used for cooking, washing, gardening and other purposes [30]. the average fresh water production all year is $4240 \mathrm{M}^{3}$ /day which is sufficient for 21200 persons in Elarish city and $4940 \mathrm{M}^{3} /$ day which is sufficient for 24700 persons in Bernis.

\section{References}

[1] Etemadi. A, Emdadi. A, AsefAfshar. O, Emami. Y, Electricity generation by the ocean thermal energy, Energy Procedia 12 (2011) 936-943.

[2] Elmohlawy. Ashraf E, Ochkov. Valery F, Kazandzhan. Boris I. Thermal performance analysis of a concentrated solar power system (CSP) integrated with natural gas combined cycle (NGCC) power plant Case Studies in Thermal Engineering 14 (2019) 100458. 
Sameh Mahmoud shaaban/ Engineering Research Journal 165 (march 2020) M22-M39

[3] Amr Omar, Amir Nashed, Qiyuan Li, Leslie Greg, Taylor. Robert A. Pathways for integrated concentrated solar power - Desalination: A critical review. (2019) 1364-0321.

[4] Shaaban S. Analysis of an integrated solar combined cycle with steam and organic Rankine cycles as bottoming cycles. Energy Convers. Manage. 2016; 126:1003-12.

[5] Darawsheh. I, Islam. MD, Banat. F. Experimental characterization of a solar powered MSF desalination process performance. Thermal Science and Engineering Progress 10 (2019) 154162.

[6] Montes MJ, Rovira A, Muñoz M, Martínez-Val JM. Performance analysis of an integrated solar combined cycle using direct steam generation in parabolic trough collectors. Appl Energy 2011; 88:3228-38.

[7] Rovira A, Montes MJ, Varela F, Gil M. Comparison of heat transfer fluid and direct steam generation technologies for integrated solar combined cycles. Appl Therm. Eng. 2013; 52:264-74.

[8] Rovira A, Barbero R, Montes MJ, Abbas R, Varela F. Comparison of heat transfer fluid and direct steam generation technologies for integrated solar combined cycles. Appl Energy 2016; 162:990-1000.

[9] Li Y, Yuan J, Yang Y. Performance analysis of a novel cascade integrated solar combined cycle system. Energy Procedia 2015; 75:540-6.

[10] Zhu G, Neises T, Turchi C, Bedilion R. Thermodynamic evaluation of solar integration into a natural gas combined cycle power plant. Renewable Energy 2015; 74:815-24.

[11] Shaaban.s. Performance optimization of an integrated solar combined cycle power plant equipped with a brine circulation MSF desalination unit. Energy Conversion and Management 198 (2019) 111794.

[12] Ozturk. M, Dincer. I, Thermodynamic analysis of a solar-based multigeneration system with hydrogen production, Appl. Therm. Eng. 51 (2013) 1235-1244.

[13] Ozlu. S, Dincer. I, Development and analysis of a solar and wind energy based multigeneration system, Sol. Energy 122 (2015) 1279-1295.

[14] Khalid. F, Dincer. I, Rosen. M.A, Energy and exergy analyses of a solar-biomass integrated cycle for multigeneration, Sol. Energy 112 (2015) 290-299.

[15] Suleman. F, Dincer. I, Agelin-Chaab. M, Development of an integrated renewable energy system for multigeneration, Energy 78 (2014) 196-204.

[16] Yang. L, Entchev. E, Ghorab. M, Lee. E.J, Kang. E.C, Energy and cost analyses of a hybrid renewable microgeneration system serving multiple residential and small office buildings, Appl. Therm. Eng. 65 (2014) 477-486.

[17] Clarke. J, McLeskey Jr. J.T, The constrained design space of double-flash geothermal power plants, Geothermics 51 (2014) 31-37.

[18] Shahzad. M.W, Ng. K.C, Thu. K, Saha. B.B, W.G. Chun, Multi effect desalination and adsorption desalination (MEDAD): a hybrid desalination method, Appl. Therm. Eng. 72 (2014) 289-297. 


\section{Sameh Mahmoud shaaban/ Engineering Research Journal 165 (march 2020) M22-M39}

[19] Kahraman. N, Cengel. Y.A, Exergy analysis of a MSF distillation plant, Energy Convers. Manag. 46 (2005) 2625-2636.

[20] Gambier A, Fertig M, Badreddin E. Hybrid modeling for supervisory control purposes for the brine heater of a multi stage flash desalination plant. Proc Am Control Conf Anchorage m (2002) 5060-5.

[21] Wade N, Callister K. on, 'Desalination: the state of the art, ' Meeting of the Institutions South Eastern Branch; 1996. p. 87-97.

[22] Al-Shayji KA. Modeling, simulation, and optimization of largescale commercial desalination plants. Dissert Doctor Philos 1998.

[23] Hawaidi EA, Mujtaba IM. Sensitivity of brine heater fouling on optimization of operation parameters of MSF desalination process using $g$ PROMS. $20^{\text {th }}$ European symposium on computer aided process engineering - ESCAPE20. 2010.

[24] El-Dessouky HI, Shaban H, Al-Ramadan H. Steady state analysis of multi stage flash desalination process. Desalination 1995; 103:271-87.

[25] Gibbons UJH. Using desalination technologies for water treatment. In: Recommended by U.S. congress, office of technology assessment, OTA-BP-O-46. Washington (DC): U.S. Government Printing Office; 1988.

[26] Helal AM. Uprating of Umm Al Nar East 4-6 MSF desalination plant. Desalination 2003; 159:43-60.

[27] Okelah MRS, Tag IA. Performance evaluation of a MSF desalination plant in Qatar. Eng J Qatar Univ 1992; 5:249-63.

[28] Wade NM. Distillation plant development and cost update. Desalination 2001; 136:3-12.

[29] Duffie. John A, Beckman. William A. Solar engineering of thermal processes. $4^{\text {th }}$ edition (2013) 978-0- 470-87366-3.

[30] El-Dessouky HT, Ettouney HM. Fundamentals of salt water desalination. 1st ed. Elsevier; 2002. 